\title{
Long-term iron accumulation in dialysis patients treated with ferric citrate hydrate: a single-center, 80-week retrospective study in Japan
}

Maki Hiratsuka ${ }^{1 *}$, Katsushi Koyama ${ }^{1}$, Kinya Sengo ${ }^{1}$, Jun Yamamoto ${ }^{1}$, Aiko Narita', Chiharu Ito ${ }^{1}$, Satoshi Kominato ${ }^{1}$, Arata Hibi ${ }^{1}$, Keisuke Kamiya', Rumi Miyahara², Junichi Fujikawa ${ }^{3}$ and Toshiyuki Miura ${ }^{1}$

\begin{abstract}
Background: Ferric citrate hydrate $(\mathrm{FCH})$, an iron-based phosphate binder, affects mineral and iron metabolism in patients with chronic kidney disease (CKD). The long-term impact of FCH on iron overload is unknown. With this study, we investigated whether the type of dialysis is associated with FCH-related iron accumulation.

Methods: This single-center, retrospectively registered, cohort study was performed in Kariya-Toyota General Hospital, Japan, among outpatients undergoing maintenance hemodialysis (HD) or peritoneal dialysis (PD) between July 2014 and January 2017. It included 136 subjects receiving FCH treatment (104 HD patients and 32 PD patients). Their iron metabolism parameters and FCH-associated adverse events were assessed over 80 weeks.

Results: In both groups, the weekly darbepoetin alpha dose and erythropoiesis resistance index declined significantly by 16 weeks, although mean hemoglobin concentrations remained stable (10-11 g/dL), and transferrin saturation peaked at 24 weeks. The difference in the weekly darbepoetin alpha dose for HD and PD patients was 16.5 and 12. $0 \mu \mathrm{g} /$ week, respectively, $(P<0.01)$. Increases in iron stores were different between the two groups. Peak mean increase in serum ferritin levels (169.0 vs. $63.0 \mathrm{ng} / \mathrm{mL}$, respectively; $P=0.001)$ in PD patients at 40 weeks was significantly earlier than that in HD patients. The adverse events observed suggest that FCH treatment was more likely to be discontinued within the first 16 weeks due to hemoglobin overshooting in HD patients and after 40 weeks due to ferritin overload in PD patients.
\end{abstract}

Conclusions: Oral iron supplementation with FCH was successful in all dialysis patients. However, the type of dialysis is a major factor associated with iron accumulation during long-term FCH treatment and more likely to occur in PD patients not experiencing regular, dialysis-associated iron loss. Therefore, the method of dialysis should be taken into consideration when evaluating iron stores of patients with CKD to determine the appropriate starting dose of FCH.

Keywords: Accumulation, Ferric citrate hydrate, Hemodialysis, Iron, Peritoneal dialysis

\footnotetext{
* Correspondence: m.hiratsuka41091@gmail.com

${ }^{1}$ Department of Nephrology, Kariya-Toyota General Hospital, 5-15

Sumiyoshi-cho, Kariya-city, Aichi Prefecture 448-8505, Japan

Full list of author information is available at the end of the article
} 


\section{Background}

Ferric citrate is a non-calcium, iron-based phosphate binder indicated for the control of serum phosphorus levels in chronic kidney disease (CKD) patients [1-3]. It is used to replete iron stores in iron deficiency anemia and reduces the requirement of intravenous iron and erythropoiesis stimulating agents (ESA) [4] and thus, ferric citrate is a dual-purpose therapeutic agent for dialysis patients. Recent studies reported that administration of ferric citrate led to decreased levels of serum fibroblast growth factor 23 (FGF23) independent of phosphate $[3,5]$, reduced the cost of anemia-management therapies [6], and was associated with fewer hospitalizations and associated costs [7].

The 2012 Kidney Disease: Improving Global Outcomes (KDIGO) guidelines recommend intravenous rather than oral iron therapy for end-stage renal disease (ESRD) dialysis patients who require ESA and/or iron supplementation, based on the higher efficacy of hemoglobin concentrations [8]. However, recent studies have focused on reevaluating the safety and availability of oral iron therapy that simultaneously delivers iron via intestinal absorption [9].

Ferric citrate hydrate (FCH, Riona $\left.{ }^{\circ}\right)$, approved in January 2014, contains $60 \mathrm{mg}$ ferric iron per $250 \mathrm{mg}$ tablet. Prescribing information warns that iron absorption from it may lead to excessive elevations in iron stores. Potential adverse effects, particularly iron overload due to long-term $\mathrm{FCH}$ use in clinical practice, are unknown. Therefore, the aim of this study was to evaluate indices of iron metabolism in hemodialysis (HD) and peritoneal dialysis (PD) patients over 80 weeks and determine whether the type of dialysis was associated with iron accumulation in ESRD patients treated with $\mathrm{FCH}$.

\section{Methods}

\section{Study design}

This retrospective, cohort study was performed at a single center where outpatients have maintenance dialysis managed by the Kariya-Toyota General Hospital, Aichi Prefecture, Japan. Indicators of iron metabolism in response to FCH therapy were compared between HD and PD patients over 80 weeks.

\section{Subjects}

Medical records for all patients treated at the center from July 2014 to January 2017 identified a total of 291 patients who underwent HD or PD. Of these, 136 patients treated with FCH were included in this study (Fig. 1). Hybrid dialysis patients (PD 6 days/week plus HD 4 h/week) were categorized as combination PD patients.

Inclusion criteria include serum phosphate $>6.0 \mathrm{mg} / \mathrm{dL}$, serum ferritin $<100 \mathrm{ng} / \mathrm{dL}$, percent transferrin saturation (TSAT) $<20 \%$, or investigator's decision. For the remaining 155 patients not treated with $\mathrm{FCH}$, the exclusion criteria was hepatic dysfunction, chronic inflammatory disease, red blood cell transfusion during the study period, malnutrition, malignancy, gastrointestinal disorder, or investigator's decision. Of the patients with FCH treatment $(n=136)$, those treated for less than 16 weeks or did not achieve a mean FCH dose of $500 \mathrm{mg} /$ day were also excluded, based on a previous study showing that iron stores were elevated after 16 weeks of FCH therapy [10]. Thus, a total of 87 patients treated with $\mathrm{FCH}$ were included in the final analysis: 62 HD patients, 25 PD patients (7 patients received combination PD). For all patients, the attending nephrologists regulated $\mathrm{FCH}$ dosage according to the Japanese Society for Dialysis Therapy (JSDT) guidelines: phosphorus 3.5$6.0 \mathrm{mg} / \mathrm{dL}$, hemoglobin $10-13 \mathrm{~g} / \mathrm{dL}$, or ferritin under $300 \mathrm{ng} / \mathrm{dL}[11,12]$. PD patients did not combine any other oral or intravenous iron if on $\mathrm{FCH}$, whereas some $\mathrm{HD}$ patients had intravenous iron (40 mg saccharated iron oxide) after weekly hemodialysis for 5 weeks (Fig. 2).

There were 49 males and 38 females, mean age was $61.9 \pm 12.5$ years, and mean dialysis duration was $5.81 \pm$ 5.90 years (Table 1 ). The primary causes of chronic renal dysfunction were diabetes mellitus 40 (46.0\%), chronic glomerulonephritis 17 (19.5\%), glomerulosclerosis 13 (15.0\%), and others 17 (19.5\%).

\section{Parameters}

Parameters of mineral and iron metabolism were routinely measured and included in this study. Phosphorus and hemoglobin were evaluated every 2-3 weeks, whereas serum ferritin, reticulocyte count, and TSAT were evaluated every 8 weeks. Weekly ESA doses were recorded and converted to equivalent darbepoetin alpha doses (conversion ratio 1:1:200). Serum ferritin was measured by a turbidimetric latex immunoassay using the LT auto Wako ferritin kit (Wako Pure Chemical Industries, Japan). Since iron metabolism is influenced by an acute phase reactant, we investigated C-reactive protein (CRP) levels over time and avoided the data when CRP was over $1.0 \mathrm{mg} / \mathrm{dL}$.

The primary endpoint was change in parameters of iron metabolism and weekly ESA doses from baseline to the end of treatment at 80 weeks. The safety endpoints were adverse events defined as changes in subjective symptoms or laboratory data. Thirteen baseline patient characteristics including the method of dialysis, diabetes mellitus, body mass index (BMI), serum phosphorus, mean $\mathrm{FCH}$ dose, hemoglobin, reticulocyte count, erythropoietin resistance index (ERI), TSAT, serum ferritin, albumin, CRP, and $\beta 2$ microglobulin were also assessed as independent risk factors for their association with increased serum ferritin from baseline to 40 weeks.

\section{Statistical analysis}

Data were presented as means \pm standard deviation. The repeated measures single-factor ANOVA was used to measure changes in the ESA dose, ERI, TSAT, and ferritin 


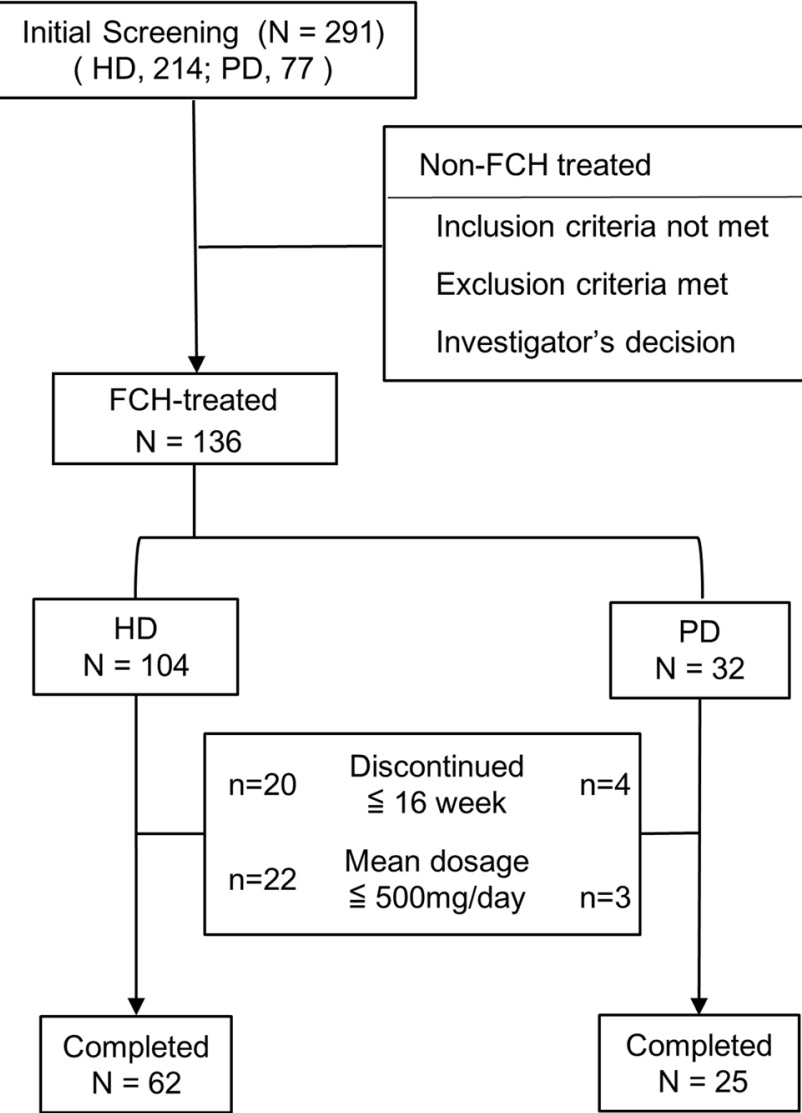

Fig. 1 Patient disposition. HD hemodialysis, PD peritoneal dialysis, FCH ferric citrate hydrate

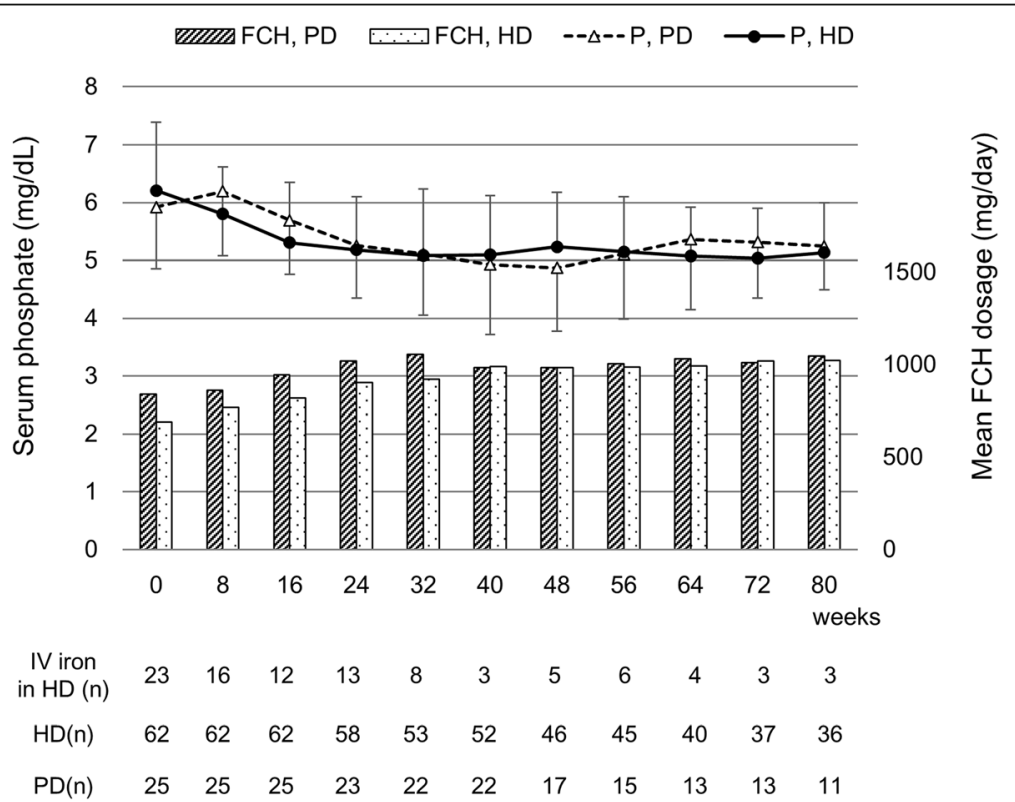

Fig. 2 Change in mean serum phosphate and FCH dosage in HD and PD patients. The number of HD patients ( $n$ ) with concomitant use of intravenous iron (40 mg saccharated iron oxide) given at the end of hemodialysis treatment once a week. The number $(n)$ of FCH-treated patients receiving HD and PD over 80 weeks. HD hemodialysis, PD peritoneal dialysis, FCH ferric citrate hydrate, $P$ serum phosphate, $N$ iron intravenous iron 
Table 1 Baseline characteristics of the study population

\begin{tabular}{|c|c|c|c|c|}
\hline Parameters & $\begin{array}{l}\text { Total } \\
N=87\end{array}$ & $\begin{array}{l}\mathrm{HD} \\
n=62\end{array}$ & VS. & $\begin{array}{l}\mathrm{PD}(\mathrm{HYB}) \\
n=25(7)\end{array}$ \\
\hline Age (years) & $61.9 \pm 12.5$ & $65.1 \pm 11.9$ & & $54.0 \pm 10.4$ \\
\hline $\begin{array}{l}\text { Gender [male/female } \\
\text { (male \%)] }\end{array}$ & $\begin{array}{l}49 / 38 \\
(56.3)\end{array}$ & $\begin{array}{l}37 / 25 \\
(59.7)\end{array}$ & & $\begin{array}{l}12 / 13 \\
(48.0)\end{array}$ \\
\hline Duration of dialysis (years) & $5.81 \pm 5.90$ & $6.38 \pm 6.56$ & & $4.42 \pm 3.51$ \\
\hline Cause of ESRD (DM \%) & $40(46.0)$ & $30(48.4)$ & & $10(40.0)$ \\
\hline \multicolumn{5}{|l|}{ Laboratory data at start } \\
\hline Hemoglobin (g/dL) & $10.0 \pm 0.80$ & $10.1 \pm 0.67$ & & $9.9 \pm 1.05$ \\
\hline Transferrin saturation (\%) & $19.1 \pm 8.86$ & $17.7 \pm 8.34$ & & $22.5 \pm 9.34$ \\
\hline Serum ferritin (ng/dL) & $52.1 \pm 43.3$ & $45.3 \pm 28.1$ & & $69.1 \pm 63.0$ \\
\hline Serum phosphate (mg/dL) & $6.13 \pm 1.15$ & $6.21 \pm 1.19$ & & $5.92 \pm 1.07$ \\
\hline $\begin{array}{l}\text { Corrected serum calcium } \\
(\mathrm{mg} / \mathrm{dL})\end{array}$ & $9.24 \pm 0.79$ & $9.16 \pm 0.77$ & & $9.45 \pm 0.82$ \\
\hline Intact PTH (pg/dL) & $\begin{array}{l}261.1 \pm \\
204.7\end{array}$ & $\begin{array}{l}228.6 \pm \\
146.3\end{array}$ & & $\begin{array}{l}341.9 \pm \\
293.6\end{array}$ \\
\hline Albumin (g/dL) & $3.65 \pm 0.38$ & $3.72 \pm 0.34$ & & $3.48 \pm 0.44$ \\
\hline C-reactive protein (mg/dL) & $0.30 \pm 0.40$ & $0.32 \pm 0.38$ & & $0.27 \pm 0.43$ \\
\hline \multicolumn{5}{|l|}{ Concomitant drugs at start } \\
\hline $\begin{array}{l}\text { Average DA dosage } \\
\text { ( } \mu \mathrm{g} / \text { week) }\end{array}$ & $34.4 \pm 24.8$ & $35.1 \pm 27.1$ & & $32.5 \pm 18.1$ \\
\hline $\begin{array}{l}\text { alV or oral iron preparations, } \\
N(\%)\end{array}$ & $34(39.1)$ & $25(40.3)$ & & $9(36.0)$ \\
\hline Calcium carbonate, N (\%) & $53(60.9)$ & $42(67.7)$ & & $11(44.0)$ \\
\hline $\begin{array}{l}\text { Sevelamer hydrochloride, } \\
N(\%)\end{array}$ & $8(9.2)$ & $3(4.8)$ & & $5(20.0)$ \\
\hline $\begin{array}{l}\text { Lanthanum carbonate, } \\
N(\%)\end{array}$ & $37(42.5)$ & $27(43.5)$ & & $10(40.0)$ \\
\hline Cinacalcet, $N(\%)$ & $20(23.0)$ & $14(22.6)$ & & $6(24.0)$ \\
\hline
\end{tabular}

Data are presented as means \pm standard deviation

$H D$ hemodialysis, $P D$ peritoneal dialysis, $H Y B$ combination therapy with PD and $H D, E S R D$ end-stage renal disease, DM diabetes mellitus, PTH parathormone, $D A$ darbepoetin alpha

aV iron, intravenous saccharated iron oxide; oral iron, ferrous citrate

from baseline to 16, 24, and 40 weeks (Fig. 3b, c, e, f). Unpaired Welch's $t$ test was used for comparisons between $\mathrm{HD}$ and PD patients for changes in serum ferritin and the mean total amount of $\mathrm{FCH}$ per day from baseline to 40 weeks or the end of treatment at 80 weeks (Fig. 4a, b). Multiple regression analysis of changes in serum ferritin levels from baseline to 40 weeks was used to identify risk factors (Table 3).

\section{Results}

In PD and HD groups, decline in the mean weekly ESA dose (darbepoetin alpha), which was significant at 16 weeks compared to the FCH therapy initiation, stabilized thereafter. Mean hemoglobin concentrations remained stable at $10-11 \mathrm{~g} / \mathrm{dL}$ (Fig. 3a, b). The ERI declined parallel to changes in weekly ESA doses and was significantly lower at 16 weeks (Fig. 3c). The mean ESA dose in the HD group decreased by $16.5 \mu \mathrm{g} /$ week
$\left(P=1.94 \times 10^{-4}\right)$ and in the PD group decreased by $12.0 \mu \mathrm{g} /$ week $(P=0.002)$. In both groups, the reticulocyte counts gradually increased throughout the period (Fig. 3d) and TSAT values increased to peak values by 24 weeks and stabilized thereafter (Fig. 3e). The average difference in TSAT was $8.2 \%\left(P=5.35 \times 10^{-6}\right)$ in the HD group and $10.9 \%(P=0.010)$ in the PD group.

Changes in serum ferritin levels were different between the groups. In HD patients, there was a gradual increase during the study period, but in PD patients, the increase was rapid, reaching peak at 40 weeks, with erratic changes observed thereafter (Fig. 3f).

Increases in serum ferritin levels from baseline to 40 or 80 weeks (Fig. 4a) were compared between the two groups. At 40 weeks, the difference was 63.0 and $169.0 \mathrm{ng} / \mathrm{mL}$ for the HD and PD groups, respectively. The increase in serum ferritin levels in PD patients was significantly higher; the difference between the two groups was $106.0 \mathrm{ng} / \mathrm{mL}$ (95\% confidence interval [CI], 175.9-27.9; $P=0.009$ ). An analysis of changes from baseline to 80 weeks revealed that the increase in mean serum ferritin levels in the HD and PD groups were not significantly different $(P=0.06)$. A comparison of changes in the mean total amount of oral FCH administered per day from baseline to either 40 or 80 weeks revealed no significant differences (Fig. 4b). Overall results indicated that increase in serum ferritin levels was more rapid in the PD group although some HD patients also used intravenous iron preparations (Fig. 2).

An assessment of $\mathrm{FCH}$-associated adverse events from baseline to the study endpoint at 80 weeks in the HD and PD groups were at 45.2 and $37.5 \%$, respectively (Table 2). The most frequent adverse event in the HD group was gastrointestinal symptoms reported by $16.3 \%$ patients, followed by hemoglobin overshooting observed in $10.6 \%$ patients within the first 16 weeks. In the PD group, ferritin overload was the most frequent adverse event observed in $15.6 \%$ patients after 40 weeks. These findings suggested that hemoglobin was more likely to increase soon after $\mathrm{FCH}$ initiation in $\mathrm{HD}$ patients whereas ferritin accumulation during the later stages of FCH therapy was more likely in PD patients.

Factors independently associated with changes in serum ferritin with FCH therapy were assessed by multiple regression analysis (Table 3 ). Thirteen variables as potential factors for iron accumulation were selected, and the outcome was changed in serum ferritin levels from baseline to 40 weeks in both groups. The dialysis method had the highest $P$ value $\left(1.23 \times 10^{-6}\right)$ with a regression coefficient $\left(R^{2}\right)$ of 105.91 (95\%CI, 66.64-145.19). BMI, baseline reticulocyte count, and ERI were also significant risk factors ( $P=0.008, P=0.002$, and $P=0.050$, respectively). Therefore, the method of dialysis was the strongest independent risk factor for iron accumulation at 40 weeks of $\mathrm{FCH}$ 


\section{a}

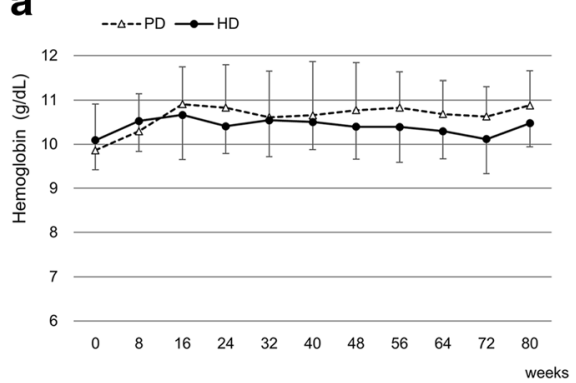

C

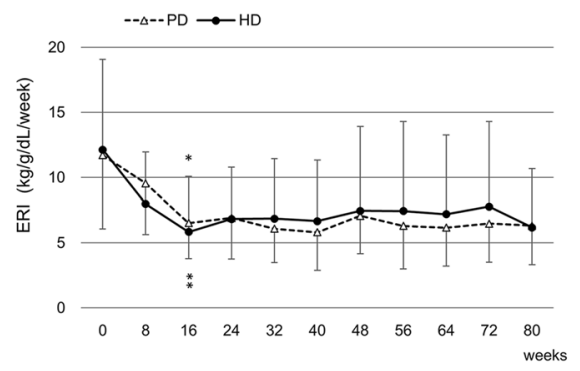

e

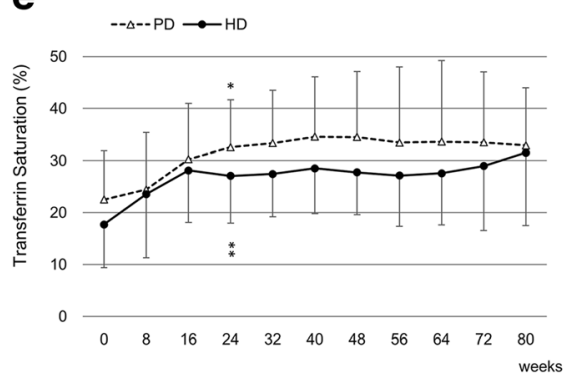

b

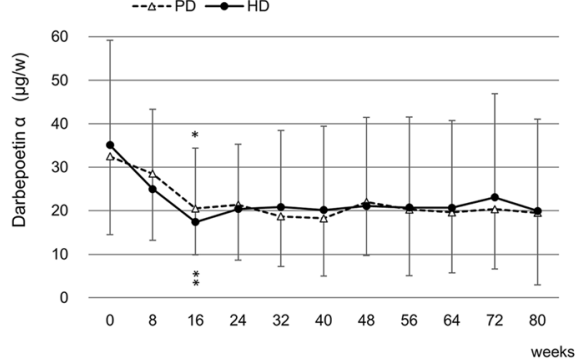

d

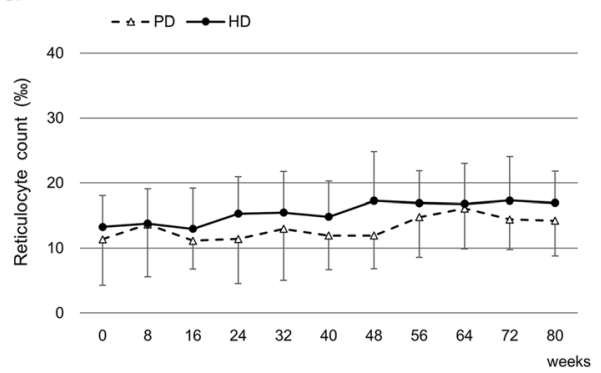

f

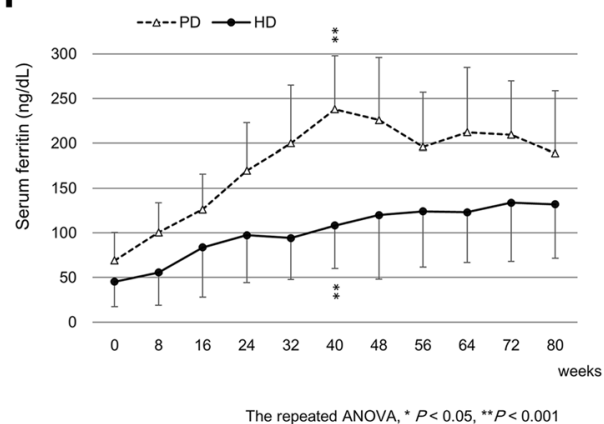

Fig. 3 Change in mean values of iron parameters in patients undergoing HD or PD treated with FCH. Data are expressed as means \pm standard deviation. The repeated measures single-factor ANOVA performed for analysis. a Hemoglobin. b Darbepoetin alpha (DA). c Erythropoiesis resistance index (ERI). d Reticulocyte count. e Transferrin saturation (TSAT). f Serum ferritin
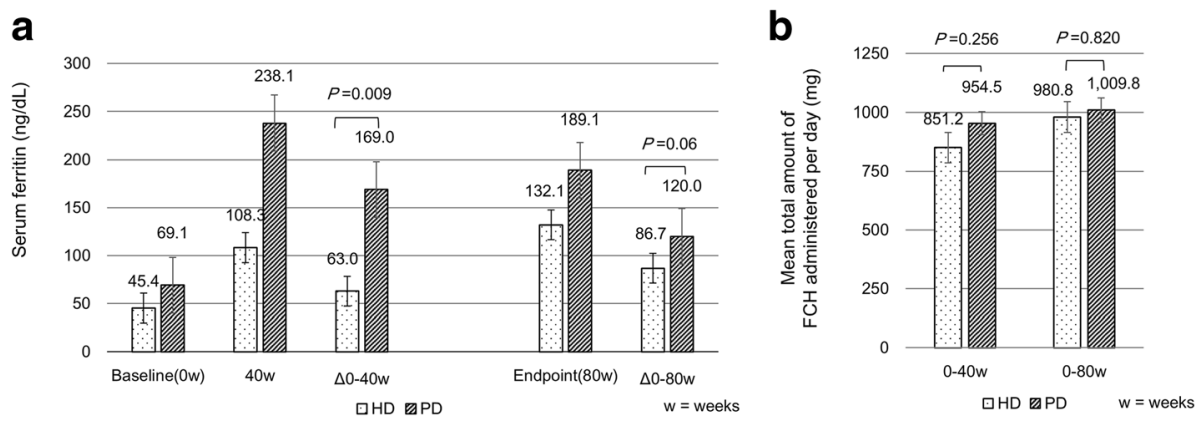

Fig. 4 Changes in mean serum ferritin levels and mean ferric citrate hydrate (FCH) dose. a Change in mean serum ferritin from baseline to 40 weeks $(\Delta 0-40 \mathrm{w})$ or from baseline to 80 weeks. b Mean total amount of $\mathrm{FCH}$ administered per day from baseline to 40 weeks ( $0-40 \mathrm{w})$ or 80 weeks $(0-80 w)$. HD hemodialysis, PD peritoneal dialysis 
Table 2 Summary of adverse events with FCH treatment

\begin{tabular}{|c|c|c|c|c|c|c|c|}
\hline \multirow{2}{*}{$\begin{array}{l}\text { Adverse events } \\
\text { Any adverse event }\end{array}$} & \multicolumn{2}{|c|}{$\begin{array}{l}\text { Total } \\
N=136(\%)\end{array}$} & \multicolumn{2}{|c|}{$\begin{array}{l}\mathrm{HD} \\
n=104(\%)\end{array}$} & \multirow[t]{2}{*}{ VS. } & \multicolumn{2}{|c|}{$\begin{array}{l}\mathrm{PD} \\
n=32(\%)\end{array}$} \\
\hline & 59 & $(43.4)$ & 47 & $(45.2)$ & & 12 & $(37.5)$ \\
\hline Hemoglobin overshoot, $>13 \mathrm{~g} / \mathrm{dL}$ & 12 & $(8.8)$ & 11 & $(10.6)$ & & 1 & $(3.1)$ \\
\hline Ferritin overload, $>300$ ng/dL & 5 & (3.6) & 0 & (0) & & 5 & (15.6) \\
\hline Gastrointestinal symptoms & 17 & $(12.5)^{a}$ & 17 & $(16.3)$ & & 0 & (0) \\
\hline Hypophosphatemia, $<3.5$ mg/dL & 5 & (3.7) & 3 & $(2.9)$ & & 2 & $(6.3)$ \\
\hline Death & 10 & $(7.4)$ & 7 & $(6.7)$ & & 3 & $(9.4)$ \\
\hline Other & 10 & $(7.4)^{\mathrm{b}}$ & 9 & $(8.7)$ & & 1 & (3.1) \\
\hline
\end{tabular}

$H D$ hemodialysis, $P D$ peritoneal dialysis

${ }^{a}$ Any digestive trouble; nine diarrhea, four constipation, four abdominal discomfort

${ }^{b}$ Other; four nothing by mounth, four darkening of stools, one itching, one eosinophilia

therapy after controlling for diabetes mellitus, BMI, serum phosphorus, mean FCH dose, hemoglobin, reticulocyte count, ERI, TSAT, ferritin, albumin, CRP, and $\beta 2$ microglobulin.

\section{Discussion}

Patients with ESRD are frequently iron deficient. Decreased iron stores are the most common reason for resistance to treatment for anemia. As per 2015 JSDT guidelines for renal anemia in chronic kidney disease, the target hemoglobin range is $10.0-12.0 \mathrm{~g} / \mathrm{dL}$ for HD patients and $11.0-13.0 \mathrm{~g} / \mathrm{dL}$ in PD patients; iron supplementation is to

Table 3 Multiple regression analysis for risk factors for increase in serum ferritin levels at 40 weeks

\begin{tabular}{|c|c|c|c|}
\hline Variables & $\begin{array}{l}\text { Regression } \\
\text { coefficient }\end{array}$ & $95 \% \mathrm{Cl}$ & $P$ value \\
\hline Method of dialysis (PD) & 105.91 & (66.64 to 145.19 ) & $<0.001^{* * *}$ \\
\hline Diabetes mellitus (1) & 10.56 & $(-23.65$ to 44.77$)$ & 0.539 \\
\hline $\begin{array}{l}\text { Body mass index } \\
\text { (per } 1 \%)\end{array}$ & -5.00 & $(-8.63$ to -1.36$)$ & $0.008^{* *}$ \\
\hline $\begin{array}{l}\text { Phosphorus } \\
\text { (per } 1 \mathrm{mg} / \mathrm{dL} \text { ) }\end{array}$ & 2.27 & $(-13.08$ to 17.63$)$ & 0.768 \\
\hline $\begin{array}{l}\text { Mean FCH dose } \\
\text { (per } 1 \mathrm{mg} / \text { day) }\end{array}$ & -2.80 & $(-13.25$ to 7.65$)$ & 0.594 \\
\hline $\begin{array}{l}\text { Hemoglobin } \\
\text { (per } 1 \mathrm{~g} / \mathrm{dL} \text { ) }\end{array}$ & 14.18 & $(-10.81$ to 39.17$)$ & 0.261 \\
\hline $\begin{array}{l}\text { Reticulocyte count } \\
\text { (per 1\%o) }\end{array}$ & 5.02 & (1.93 to 8.12$)$ & $0.002^{* *}$ \\
\hline $\begin{array}{l}\text { Erythropoiesis resistance } \\
\text { index (per 1) }\end{array}$ & 2.55 & (0.00 to 5.10$)$ & $0.050^{*}$ \\
\hline $\begin{array}{l}\text { Transferrin saturation } \\
\text { (per 1\%) }\end{array}$ & -1.63 & $(-3.73$ to 0.48$)$ & 0.127 \\
\hline Ferritin (per $1 \mathrm{ng} / \mathrm{mL}$ ) & -0.10 & $(-0.62$ to 0.41$)$ & 0.687 \\
\hline Albumin (per $1 \mathrm{~g} / \mathrm{dL}$ ) & 42.56 & $(-10.06$ to 95.18$)$ & 0.111 \\
\hline $\begin{array}{l}\text { C-reactive protein } \\
\text { (per } 1 \mathrm{mg} / \mathrm{dL} \text { ) }\end{array}$ & -35.00 & (-84.85 to 14.86$)$ & 0.165 \\
\hline $\begin{array}{l}\text { ß2-microglobulin } \\
\text { (per } 1 \mathrm{mg} / \mathrm{L} \text { ) }\end{array}$ & -1.42 & $(-4.66$ to 1.81$)$ & 0.382 \\
\hline
\end{tabular}

$C l$ confidence interval, $P D$ peritoneal dialysis, $F C H$ ferric citrate hydrate ${ }^{*} P<0.05,{ }^{* *} P<0.01,{ }^{* * *} P<0.001$ begin if TSAT is $<20 \%$ and/or serum ferritin $<100 \mathrm{ng} / \mathrm{mL}$, and discontinued if serum ferritin is $>300 \mathrm{ng} / \mathrm{mL}$. Several guidelines recommend intravenous iron therapy for superior efficacy over oral therapy. However, others caution against potential toxicities induced by intravenous iron therapy and subsequent increases in mortality, cardiovascular diseases, and infections [13-16]. Therefore, the ironbased phosphate binder, $\mathrm{FCH}$, was recently reassessed because it affects both mineral and iron metabolism and delivers iron by oral intake. As oral iron works via a "mucosal block" in the intestine, the ability of selfregulated iron absorption $[17,18], \mathrm{FCH}$, is more effective for maintaining hemoglobin levels or more safety for not increased inflammatory makers and oxidative stress if the serum ferritin level is less than $100 \mathrm{ng} / \mathrm{dl}$ [19-21]. Despite dual benefits, FCH has a narrow therapeutic index and could simultaneously put the patient at risk for increased hemoglobin levels and iron accumulation.

The findings of the present study indicated that in PD and $\mathrm{HD}$ patients, $\mathrm{FCH}$ was successful in treating iron deficiency anemia and reducing the necessity of ESA in maintaining target hemoglobin levels. Changes in hemoglobin levels occurred early within the first 16 weeks, TSAT reached peak at 24 weeks, and reticulocyte count showed a gradual increase throughout the period. These findings, in conjunction with the adverse events, suggest that overshooting hemoglobin levels are more likely in HD patients within the first 16 weeks.

Another significant difference between the groups was the changing rate of iron accumulation, which occurred earlier in PD patients. As a phosphate binder, the $\mathrm{FCH}$ dose was increased in some patients with serum phosphate levels above $6.0 \mathrm{mg} / \mathrm{dL}$, subsequently serum ferritin concentrations also increased over $300 \mathrm{ng} / \mathrm{dL}$ by 40 weeks. Some PD patients discontinued FCH or decreased the dose, and others who continued FCH could reduce dietary iron absorption due to elevated hepcidin concentrations as high hepcidin or ferritin levels block intestinal iron absorption. In contrast, iron accumulation, reflected in increased serum ferritin levels, was gradual over the 80- 
week study period in HD patients who routinely suffer iron loss due to the dialysis procedure itself, this does not occur in PD.

Consequently, the method of dialysis should be taken into consideration during the assessment of iron stores in CKD patients for accurate determination of the $\mathrm{FCH}$ starting dose. We suggest that patients should be started on relatively small doses of $\mathrm{FCH}$ to minimize the risk of elevated hemoglobin and ferritin levels. Long-term continuous FCH therapy is essential for achieving maximum benefit; therefore, other phosphate binders should be considered to maintain serum phosphorus levels below $6.0 \mathrm{ml} / \mathrm{dL}$.

The adverse events observed in this cohort indicated that the hemoglobin overshoot occurred within the first 16 weeks in HD patients and ferritin overload occurred after 40 weeks in PD patients. Simultaneously, HD patients suffered gastrointestinal reactions earlier than PD patients. Prescribing information for $\mathrm{FCH}$ from the clinical trial in Japan reported these side effects in 17.1\% HD patients and $30.4 \%$ PD patients. Our study had different results, and the reasons for this are unclear. A possible explanation is that HD patients suffer severe iron deficiency due to iron loss, and consequently, their digestive tract has a more intense, iron burden that causes gastrointestinal reactions.

Limitations of the current study are the following: The number of patients was small especially in the PD group in this single-center study, and future multi-center studies with larger cohorts are necessary. The study did not have extended observation periods, and evaluation of $\mathrm{FCH}$-induced increments of serum ferritin associated with clinical outcomes such as infection, cardiovascular events, and mortality, these should be studied in the future.

\section{Conclusions}

Oral FCH therapy is successful as iron supplementation for dialysis patients. However, there was an association between the dialysis method and iron accumulation with long-term FCH therapy. Serum ferritin levels were higher in PD patients than those receiving HD. Therefore, the method of dialysis should be taken into consideration when evaluating iron stores of patients with CKD to determine the appropriate starting dose of FCH.

\section{Abbreviations}

CKD: Chronic kidney disease; CRP: C-reactive protein; ERI: Erythropoietin resistance index; ESA: Erythropoiesis stimulating agent; ESRD: End-stage renal disease; FCH: Ferric citrate hydrate; HD: Hemodialysis; PD: Peritoneal dialysis; TSAT: Transferrin saturation

\section{Acknowledgements}

The authors are grateful to all the medical staff who participated in this study, especially KK, JF, and RM.
Funding

There is no funding to be disclosed.

\section{Availability of data and materials}

The datasets used and/or analyzed during the current study are available from the corresponding author upon reasonable request.

\section{Authors' contributions}

$\mathrm{MH}$ was involved in the study design, study procedure implementation, data analysis and article writing of the manuscript. KKo reviewed the study design and interpretation of results. JF and RM contributed to clinical data collection. $\mathrm{KS}, J Y, A N, \mathrm{Cl}, \mathrm{SK}, \mathrm{AH}, \mathrm{KKa}$ and TM participated in the study. All authors read and approved the final manuscript.

\section{Competing interests}

The authors declare that they have no competing interests.

\section{Consent for publication}

Not applicable.

\section{Ethics approval and consent to participate}

This study was conducted in accordance with the Declaration of Helsinki and approved by the institutional review board in Kariya-Toyota General Hospital, (approval number 251).

\section{Publisher's Note}

Springer Nature remains neutral with regard to jurisdictional claims in published maps and institutional affiliations.

\section{Author details}

${ }^{1}$ Department of Nephrology, Kariya-Toyota General Hospital, 5-15 Sumiyoshi-cho, Kariya-city, Aichi Prefecture 448-8505, Japan. ${ }^{2}$ Department of Pharmacy, Kariya-Toyota General Hospital, Kariya, Japan. ${ }^{3}$ Department of Clinical Engineering Technology, Kariya-Toyota General Hospital, Kariya, Japan.

Received: 18 December 2016 Accepted: 31 May 2017

Published online: 05 September 2017

\section{References}

1. Dwyer JP, Sika M, Schulman G, et al. Dose-response and efficacy of ferric citrate to treat hyperphosphatemia in hemodialysis patients: a short-term randomized trial. Am J Kidney Dis. 2013;61(5):759-66.

2. Yokoyama K, Akiba T, Fukagawa M, et al. JTT-751 for treatment of patients with hyperphosphatemia on peritoneal dialysis. Nephron Clin Pract. 2014; 128(1-2):135-40.

3. Yokoyama K, Hirakata H, Akiba T, Fukagawa M, Nakayama M, Sawada K, et al. Ferric citrate hydrate for the treatment of hyperphosphatemia in nondialysis-dependent CKD. Clin J Am Soc Nephrol. 2014;9(3):543-24.

4. Lewis JB, Sika M, Koury MJ, et al. Ferric citrate controls phosphorus and delivers iron in patients on dialysis. J Am Soc Nephrol. 2015;26(2):493-503.

5. Iguchi A, Kazama JJ, Yamamoto S, et al. Administration of ferric citrate hydrate decreases circulating FGF23 levels independently of serum phosphate levels in hemodialysis patients with iron deficiency. Nephron. 2015;131(3):161-6.

6. Thomas A, Peterson LE. Reduction of costs for anemia-management drugs associated with the use of ferric citrate. Int J Nephrol Renov Dis. 2014;7:191-201.

7. Rodby R, Umanath K, Niecestro R, et al. Phosphorus binding with ferric citrate is associated with fewer hospitalizations and reduced hospitalization costs. Expert Rev Pharmacoecon Outcomes Res. 2015;15:545-50.

8. Kidney Disease Improving Global Outcomes (KDIGO). Clinical practice guideline for anemia in chronic kidney disease. Kidney Int. 2012;Suppl 2:292-8

9. Daimon S, Mizushima I. Effect of oral and intravenous iron therapy on hemoglobin levels in hemodialysis patients according to serum ferritin level. Renal Replacement Therapy. 2016;2:63.

10. Yokoyama K, Akiba T, Fukagawa M, et al. Long-term safety and efficacy of a novel iron-containing phosphate binder, JTT-751, in patients receiving hemodialysis. J Ren Nutr. 2014;24(4):261-7.

11. Tsubakihara Y, Nishi S, Akiba T, et al. 2008 Japanese Society for Dialysis Therapy: guidelines for renal anemia in chronic kidney disease. Ther Apher Dial. 2010;14(3):240-275.14. 
12. Fukagawa M, Yokoyama K, Koiwa F, et al. Clinical practice guideline for the management of chronic kidney disease-mineral and bone disorder. Ther Apher Dial. 2013;17(3):247-88.

13. Yoshimura K, Nakano H, Yokoyama K, et al. High iron storage levels are associated with increased DNA oxidative injury in patients on regular hemodialysis. Clin Exp Nephrol. 2005;9(2):158-63.

14. Bailie GR, Larkina M, Goodkin DA, et al. Data from the Dialysis Outcomes and Practice Patterns Study validate an association between high intravenous iron doses and mortality. Kidney Int. 2015;87(1):162-8.

15. Kuo KL, Hung SC, Lin YP, et al. Intravenous ferric chloride hexahydrate supplementation induced endothelial dysfunction and increased cardiovascular risk among hemodialysis patients. PLoS One. 2012;7:e50295

16. Brookhart MA, Freburger JK, Ellis AR, et al. Infection risk with bolus versus maintenance iron supplementation in hemodialysis patients. J Am Soc Nephrol. 2013;24(7):1151-8.

17. Frazer DM, Wilkins SJ, Becker EM, et al. A rapid decrease in the expression of DMT1 and Dcytb but not Ireg1 or hephaestin explains the mucosal block phenomenon of iron absorption. Gut. 2003;52(3):340-6.

18. Galy B, Ferring-Appel D, Becker C, et al. Iron regulatory proteins control a mucosal block to intestinal iron absorption. Cell Rep. 2013;3(3):844-57.

19. Nakanishi T, Kuragano T, Kaibe $S$, et al. Should we reconsider iron administration based on prevailing ferritin and hepcidin concentrations? Clin Exp Nephrol. 2012;16(6):819-26

20. Van Buren PN, Lewis JB, Dwyer JP, et al. The phosphate binder ferric citrate and mineral metabolism and inflammatory markers in maintenance dialysis patients: results from prespecified analyses of a randomized clinical trial. Am J Kidney Dis. 2015;66(3):479-88.

21. Tanaka M, Miyamura S, Imafuku T, et al. Effect of a ferric citrate formulation, a phosphate binder, on oxidative stress in chronic kidney diseases-mineral and bone disorder patients receiving hemodialysis: a pilot study. Biol Pharm Bull. 2016:39(6):1000-6.

\section{Submit your next manuscript to BioMed Central and we will help you at every step:}

- We accept pre-submission inquiries

- Our selector tool helps you to find the most relevant journal

- We provide round the clock customer support

- Convenient online submission

- Thorough peer review

- Inclusion in PubMed and all major indexing services

- Maximum visibility for your research

Submit your manuscript at www.biomedcentral.com/submit 